\title{
Adrenopause or decline of serum adrenal androgens with age in women living at sea level or at high altitude
}

\author{
G F Gonzales, C Góñez and A Villena \\ Department of Physiological Sciences, Faculty of Sciences and Philosophy and Instituto de Investigaciones de la Altura, Universidad Peruana Cayetano \\ Heredia, PO Box 1843, Lima, Peru \\ (Requests for offprints should be addressed to G F Gonzales, Department of Physiological Sciences, Universidad Peruana Cayetano Heredia, PO Box 1843, \\ Lima, Peru; Email: iiad@upch.edu.pe)
}

\begin{abstract}
The present study aimed to determine adrenopause or reduction of serum adrenal androgens with age at high altitude and at sea level. It was a cross-sectional study performed in 210 women resident at high altitude $(4340 \mathrm{~m})$ and 123 women living in Lima $(150 \mathrm{~m})$, aged 20-70 years. Fasting early morning blood samples were obtained. Serum dehydroepiandrosterone (DHEA), DHEA sulphate (DHEAS), androstenedione, testosterone and estradiol were measured by radioimmunoassay. Serum testosterone concentrations were greater in women living at high altitude than in those resident at sea level. Serum concentrations of DHEA, DHEAS and androstenedione were lower in women living at high altitude than in those living at sea level. The DHEAS/DHEA ratio was significantly greater, and the androstenedione/testosterone ratio was lower in samples from women living at high altitude. Among women older than 50 years of age, a greater decline in serum concentrations of DHEA was observed in those living at high altitude than in those living at sea level. Among women 60-70 years of age, serum concentrations of DHEA at high altitude were $46.9 \%$ of those in women of the same age living at sea level. Decay of DHEAS at sea level and at high altitude occurred from the age of 40 years. The decline was faster at high altitude than at sea level, and in women aged 60-70 years serum values
\end{abstract}

of DHEAS at high altitude were $56 \%$ of those at sea level. In the same age group, serum concentrations of androstenedione among those native to high altitudes were $27 \cdot 34 \%$ of the value at sea level. At sea level, serum testosterone concentrations did not change with age from 20 to 70 years. In women aged 20-39 years and 50-59 years, serum testosterone concentrations were greater at high altitude than at sea level $(P<0 \cdot 05)$. In those aged 60-70 years, the concentrations were similar in those living at sea level and at high altitude. At sea level and at high altitude, the serum testosterone/estradiol ratio increased with age $(P<0.0034$ and $P<0.0001$ respectively). This ratio increased at an earlier age among those living at high altitude (40-49 years) than among those living at sea level (50-59 years). Multivariate analysis showed that altitude $(P<0 \cdot 0001)$ and greater chronological age $(P<0 \cdot 001)$ were associated with lower serum DHEAS concentrations. DHEAS was related to chronological age $(P<0 \cdot 0001)$. Low serum androstenedione concentrations were related to living at high altitude at birth and greater chronological age $(P<0 \cdot 0001)$. In conclusion, adrenopause is attained earlier and is of greater magnitude at high altitude than at sea level.

Journal of Endocrinology (2002) 173, 95-101

\section{Introduction}

Human aging involves a series of chronological processes including shortening of telomeres of the chromosomes, mitochondrial aging, accumulation of mutations, and expression of genes of aging, among others (Bowles 1998).

In women, aging is accompanied by a decline in circulating concentrations of components of the growth hormone-insulin-like growth factor I axis (Corpas et al. 1993), the adrenal sex steroid precursors - dehydroepiandrosterone (DHEA) and its sulphated ester (DHEAS) - and ovarian sex hormones (BirkenhagerGillesse et al. 1994, Lamberts et al. 1997, Semezuk 1998).
These processes define somatopause, adrenopause and menopause respectively. Somatopause and adrenopause are associated with general aging (Ravaglia et al. 1996, Morales et al. 1998), whereas menopause is the expression of reproductive aging (Soules et al. 1998, Te Velde et al. $1998 a, b)$. There is some evidence that both general aging and reproductive aging are related (Dorland et al. 1998, Kirkwood 1998). Furthermore, there is a strong association between age at natural menopause and age at death (Snowdon et al. 1989, Snowdon 1990, WHO 1996).

DHEA and its sulphated metabolite DHEAS are the main products of the zona reticularis of the human adrenal glands (Biekenhager-Gillese et al. 1994). DHEA is 
quantitatively the most important steroid in the human body (Vermeulen 1997). It has been suggested that DHEA may intervene in processes of maturation (Góñez et al. 1993) and aging (Vermeulen 1997, Morales et al. 1998).

Serum concentrations of DHEA decline significantly, starting from the age of 30 years, when the maximal value is attained (Labrie et al. 1997). Treatment with DHEA for 3 (Morales et al. 1994) or 6 months (Morales et al. 1998) resulted in improvement of physical and psychological well-being in aged men and women.

Gonzales \& Villena (1997) and León-Velarde et al. (1997) have demonstrated that median age at menopause occurs earlier at high altitudes in the Central Andes than at sea level in Peru. It is known that women of a younger age at menopause also have a lower life expectancy (WHO 1996). In Cerro de Pasco at $4340 \mathrm{~m}$, located in the central Andes of Peru, life expectancy is shorter than at sea level (León-Velarde \& Arregui 1994).

According to these data, general aging may be attained early in populations living at high altitudes. If aging is occurring early at high altitude, and if a relationship between serum adrenal androgen concentrations and age is accepted, it is possible that the decline in serum adrenal androgen concentrations may occur earlier in women living at high altitude than in those at sea level.

The present study was designed to determine serum concentrations of adrenal androgens (DHEA, DHEAS and androstenedione), testosterone and estradiol in women of different ages living at sea level and at high altitude.

\section{Materials and Methods}

\section{Study design}

This was a cross-sectional study comparing women of different ages resident at sea level and at high altitude. During sample analysis, serum collected from women living at both sea level and high altitude were included in the same assay run, to reduce between-assay variation.

\section{Study participants}

The study was performed in 210 women who were native to high altitude, residing at Cerro de Pasco, Peru (4340 m) and aged 20-70 years, who had lived in the place of study for at least 10 years without significant migrations to or from different altitudes. As a control group, we studied 123 women aged 20-70 years, living in Lima at $150 \mathrm{~m}$ above sea level. The women were grouped according to age: 20-29 years, 30-39 years, 40-49 years, 50-59 years and $>59$ years. We chose to study about 20 women for each age group at sea level and double the number at Cerro de Pasco.

Women from Lima were of the same ethnic group as those at high altitude.
Data were obtained through a structured interview or by written questionnaires. They included chronological age, place of birth, altitude of birthplace, age at first and last menses, and total number of pregnancies. Smoking was observed in fewer than $1 \%$ of the women included in the study.

Menopause was defined as cessation of menses at least 12 months before the interview. Postmenopausal women receiving hormone replacement therapy were excluded from the study. None of those included in the study had been taking any medication during the last 3 months before the study.

Height and weight were measured in each woman. Body mass index (BMI) was calculated according to the equation weight $(\mathrm{kg}) /$ height $(\mathrm{m})^{2}$.

A fasting venous blood sample was obtained from each woman between 08:00 and 10:00 h, to avoid circadian variations. In premenopausal women, the part of the cycle chosen for blood sampling was not different between those living at sea level and at high altitude (mean \pm S.D. day of cycle: $13 \cdot 80 \pm 9 \cdot 60$ and $16 \cdot 07 \pm 10 \cdot 15$, at high altitude and sea level respectively; NS).

\section{Measurements of serum estradiol and testosterone concentrations}

Serum estradiol and testosterone concentrations were measured by radioimmunoassay using commercially available kits (Diagnostic Products Co., Los Angeles, CA, USA): catalogue number TKE25 for estradiol and TKTT5 for testosterone. The within-assay variations were $6.4 \%$ for estradiol and $5.5 \%$ for testosterone. Sensitivity of the testosterone assay was $4.0 \mathrm{pg} / \mathrm{ml}$ and that for the estradiol assay was $1.5 \mathrm{pg} / \mathrm{ml}$.

\section{Measurements of DHEA, DHEAS and androstenedione concentrations}

The serum adrenal androgen concentrations were measured by RIA using commercial kits (Diagnostic Products Co.): catalogue number TKDS5 for DHEAS, TKDH2 for DHEA and TKAN2 for androstenedione. DHEA was assayed after anhydrous ethyl ether extraction. For measurement of DHEAS and androstenedione, no extraction procedure was required. The within-assay variations were $4 \%$ for DHEAS, $7 \%$ for DHEA and 5\% for androstenedione.

The DHEA/androstenedione ratio was used as marker of $3 \beta$-hydroxysteroid dehydrogenase activity. DHEAS/ DHEA, androstenedione/testosterone, and testosterone/ estradiol ratios were also calculated, as markers of the metabolism of DHEAS, androstenedione and testosterone respectively.

\section{Statistical analysis}

Data were analysed using the STATA (version 4.0) program (Stata Corporation, College Station, TX, USA). 
Table 1 Selected physiological variables at sea level and at high altitude. Data are mean \pm S.D.

\begin{tabular}{|c|c|c|}
\hline & Sea level & High altitude \\
\hline \multicolumn{3}{|l|}{ Variable } \\
\hline Age (years) & $43 \cdot 62 \pm 12 \cdot 31$ & $42 \cdot 84 \pm 10 \cdot 95$ \\
\hline Age at menarche (years) & $13 \cdot 30 \pm 1 \cdot 63$ & $14 \cdot 29 \pm 1 \cdot 56^{* *}$ \\
\hline Age at menopause (years) & $47 \cdot 00 \pm 3 \cdot 28$ & $45 \cdot 31 \pm 3 \cdot 13^{*}$ \\
\hline Post menopausal years & $10 \cdot 35 \pm 5 \cdot 09$ & $8 \cdot 28 \pm 6 \cdot 80$ \\
\hline Pregnancies $(n)$ & $4 \cdot 68 \pm 3 \cdot 26$ & $6 \cdot 22 \pm 3 \cdot 72^{* *}$ \\
\hline Body mass index $\left(\mathrm{kg} / \mathrm{m}^{2}\right)$ & $26 \cdot 34 \pm 4 \cdot 00$ & $25 \cdot 88 \pm 4 \cdot 11$ \\
\hline Pulse oxygen saturation (\%) & $98 \cdot 39 \pm 1 \cdot 83$ & $87 \cdot 73 \pm 3 \cdot 83^{* *}$ \\
\hline Serum testosterone $(\mathrm{pg} / \mathrm{ml})$ & $62 \cdot 61 \pm 63 \cdot 09$ & $95 \cdot 02 \pm 106 \cdot 86^{* *}$ \\
\hline Serum estradiol $(\mathrm{pg} / \mathrm{ml})$ & $63 \cdot 21 \pm 69 \cdot 99$ & $79 \cdot 45 \pm 99 \cdot 23$ \\
\hline DHEA $(\mathrm{ng} / \mathrm{ml})$ & $1 \cdot 99 \pm 1 \cdot 27$ & $1 \cdot 22 \pm 1 \cdot 40^{* *}$ \\
\hline DHEAS $(\mu \mathrm{g} / \mathrm{ml})$ & $149 \cdot 7 \pm 82 \cdot 7$ & $90 \cdot 9 \pm 63 \cdot 6^{* *}$ \\
\hline Androstenedione (ng/ml) & $1.66 \pm 0.62$ & $1 \cdot 00 \pm 0 \cdot 86^{* *}$ \\
\hline DHEAS/DHEA ratio & $87 \cdot 29 \pm 47 \cdot 02$ & $149 \cdot 12 \pm 145 \cdot 14^{* *}$ \\
\hline DHEA/androstenedione ratio & $0.99 \pm 0.44$ & $1 \cdot 41 \pm 1 \cdot 82$ \\
\hline Androstenedione/testosterone ratio & $7 \cdot 10 \pm 8 \cdot 52$ & $1 \cdot 97 \pm 2 \cdot 86^{* * *}$ \\
\hline
\end{tabular}

DHEA, dehydroepiandrosterone; DHEAS, dehydroepiandrosterone sulphate. ${ }^{*} P<0 \cdot 05$; ${ }^{* *} P<0 \cdot 01$;

${ }^{* * *} P<0 \cdot 0001$ with respect to values at sea level (Student's $t$-test).

For quantitative data, homogeneity of variances was assessed by the Bartlett test. If variances were homogeneous, differences between groups were assessed by one-way analysis of variance. Differences between pair of means were assessed by the Scheffé test. When variances were not homogeneous, the Wilcoxon range test was used.

Single and multiple linear regression analyses were performed to assess the independent effect of age, hormone concentrations and BMI on serum concentrations of adrenal androgens.

A value of $P<0.05$ was considered to be statistically significant.

\section{Results}

Chronological age, postmenopausal years, BMI and serum concentrations of estradiol were similar in the samples collected from women living at sea level and those living at high altitude. Age at menarche, total number of pregnancies, and serum testosterone concentrations were greater in women living at high altitude than in those living at sea level. Menopause was attained at an earlier age in women at high altitude than among those living at sea level $(P<0 \cdot 05)$. Pulse oxygen saturation and serum concentrations of DHEA, DHEAS and androstenedione were lower in samples collected from women living at high altitude. The DHEAS/DHEA ratio was significantly greater, and the androstenedione/testosterone ratio was lower, in samples from women living at high altitude (Table 1).

At sea level and at high altitude, the greatest serum concentrations of DHEA were observed in women between 20 and 29 years of age. Thereafter, a progressive and significant decline in the serum hormone concentrations was observed: at sea level, the value in women aged $60-70$ years was $35.8 \%$ that at $20-29$ years, whereas at high altitude the value at $60-70$ years declined to $25 \%$ of that at 20-29 years.

In women aged from 20 to 39 years, serum concentrations of DHEA were lower in women living at high altitude than in those resident at sea level. In the group aged 40-49 years, serum concentrations of DHEA were similar in those at sea level and at high altitude (NS). After the age of 50 years, a greater decline in serum concentrations of DHEA was observed in women living at high altitude than in those at sea level, and by 60-70 years of age the serum concentrations among those resident at high altitude were $46.9 \%$ of those in women resident at sea level (Table 2).

The greatest concentrations of serum DHEAS were observed among women aged 20-29 years living at sea level, and those aged 30-39 years living at high altitude. Serum concentrations of DHEAS among women aged 30-39 years were similar at both altitudes of residence. The decline in DHEAS at sea level and at high altitude occurred from 40 years of age and was faster at high altitude than at sea level. At 60-70 years, the serum concentration of DHEAS among those living at high altitude was $56 \%$ of that at sea level (Table 2).

In women aged 20-29 years, serum concentrations of androstenedione were similar in those living at sea level and at high altitude, whereas in those aged 30-39 years serum concentrations of androstenedione were significantly lower in those resident at high altitude $(P<0 \cdot 005)$. The difference disappeared at 40-49 years and thereafter was evident again at 50-70 years (Table 2 ). 
Table 2 Serum concentrations of DHEA, DHEAS, androstenedione and testosterone in women resident at sea level or at high altitude, according to chronological age. Data are means \pm S.D.

\begin{tabular}{|c|c|c|c|c|c|c|c|c|}
\hline & \multicolumn{2}{|c|}{ DHEA (ng/ml) } & \multicolumn{2}{|c|}{ DHEAS $(\mu \mathrm{g} / \mathrm{ml})$} & \multicolumn{2}{|c|}{ Androstenedione (ng/ml) } & \multicolumn{2}{|c|}{ Testosterone (pg/ml) } \\
\hline & Sea level & High altitude & Sea level & High altitude & Sea level & High altitude & Sea level & High altitude \\
\hline \multicolumn{9}{|c|}{ Age (years) } \\
\hline $30-39$ & $1 \cdot 62 \pm 0.56$ & $0 \cdot 86 \pm 0 \cdot 56^{*}$ & $183 \cdot 3 \pm 79 \cdot 7$ & $155 \cdot 5 \pm 98 \cdot 4$ & $1 \cdot 74 \pm 0 \cdot 21$ & $1 \cdot 21 \pm 0 \cdot 44^{* *}$ & $71 \cdot 8 \pm 48 \cdot 4$ & $100 \cdot 9 \pm 87 \cdot 2^{*}$ \\
\hline $40-49$ & $1 \cdot 58 \pm 0 \cdot 78$ & $1 \cdot 39 \pm 0 \cdot 70$ & $103 \cdot 2 \pm 52 \cdot 9$ & $72 \cdot 3 \pm 28 \cdot 1^{*}$ & $1.52 \pm 0.56$ & $1 \cdot 05 \pm 1 \cdot 14$ & $67 \cdot 1 \pm 75 \cdot 8$ & $81 \cdot 5 \pm 90 \cdot 4$ \\
\hline $50-59$ & $1 \cdot 16 \pm 0 \cdot 34$ & $0.54 \pm 0.42^{*}$ & $100 \cdot 4 \pm 35 \cdot 9$ & $64 \cdot 6 \pm 35 \cdot 3^{*}$ & $1 \cdot 32 \pm 0 \cdot 44$ & $0.59 \pm 0.49 * *$ & $29 \cdot 2 \pm 27 \cdot 4$ & $84 \cdot 4 \pm 116 \cdot 4^{*}$ \\
\hline
\end{tabular}

${ }^{*} P<0 \cdot 05 ;{ }^{* * P} P 0 \cdot 01$ with respect to values at sea level.

The greatest concentrations of androstenedione among women living at sea level and at high altitude were observed at 20-29 years. Serum concentrations of androstenedione among natives of high altitude aged $60-70$ years were $27 \cdot 34 \%$ of the value in those living at sea level. In samples from both sea-level and high-altitude groups, serum concentrations of androstenedione declined with age from 20 to 70 years (Table 2).

Among women living at sea level, serum testosterone concentrations did not change with age from 20 to 70 years. In those living at high altitude, the greatest mean values were observed at 20-29 years of age, whereas the values at $60-70$ years were $33 \%$ lower. In women in age groups $20-39$ years and 50-59 years, serum testosterone concentrations were greater at high altitude than at sea level $(P<0 \cdot 05)$. In those aged $60-70$ years, serum testosterone concentrations were similar in women living at sea level or at high altitude (Table 2).

At sea level and at high altitude, the serum testosterone/ estradiol ratio increased with age $(P<0.0034$ and $P<0 \cdot 0001$ respectively). This ratio increased earlier in those resident at high altitude (40-49 years) than in women living at sea level (50-59 years). At 60-70 years, there were no differences between the two altitude groups with respect to serum testosterone/estradiol ratios (Table 3).

Table 3 Serum testosterone/estradiol ratio in women resident at sea level or at high altitude, according to chronological age. Data are mean \pm S.D.

\begin{tabular}{|c|c|c|c|}
\hline & \multicolumn{2}{|c|}{ Testosterone/estradiol ratio } & \multirow[b]{2}{*}{$\boldsymbol{P}$} \\
\hline & Sea level* & High altitude** & \\
\hline \multicolumn{4}{|c|}{ Age (years) } \\
\hline $20-29$ & $2 \cdot 0 \pm 1 \cdot 0$ & $8 \cdot 0 \pm 28 \cdot 5$ & NS \\
\hline $30-39$ & $1 \cdot 0 \pm 1 \cdot 2$ & $1 \cdot 3 \pm 1 \cdot 8$ & NS \\
\hline $40-49$ & $1 \cdot 2 \pm 1 \cdot 7$ & $20 \cdot 3 \pm 46 \cdot 1$ & $<0.05$ \\
\hline $50-59$ & $22 \cdot 4 \pm 24 \cdot 4$ & $65 \cdot 2 \pm 100 \cdot 2$ & $<0.05$ \\
\hline $60-70$ & $82 \cdot 0 \pm 123 \cdot 8$ & $50 \cdot 2 \pm 64 \cdot 8$ & NS \\
\hline
\end{tabular}

${ }^{*} P<0 \cdot 0034 ;{ }^{*} P<0 \cdot 0001$ with respect to age.
Multivariate analysis showed that altitude $(P<0 \cdot 0001)$ and greater chronological age $(P<0 \cdot 001)$ were associated with lower serum concentrations of DHEAS (Table 4). In Table 5, data are presented showing independent variables associated with serum concentrations of DHEAS, DHEA and androstenedione at high altitude. DHEAS was related to chronological age $(P<0 \cdot 0001)$. Serum DHEA concentrations were not related to any of the variables included in the equation. Low serum androstenedione concentrations were related to residence at high altitude at birth and greater chronological age $(P<0 \cdot 0001)$.

\section{Discussion}

Our results demonstrate that adrenopause, the decline in serum adrenal androgens with age, occurred earlier in women resident at high altitude than in those living at sea level. As adrenopause is a marker of somatic aging (Berr et al. 1996, Ravaglia et al. 1996, Labrie et al. 1998), we postulate that somatic aging will also occur early at high altitude.

The greatest concentrations of serum DHEA at sea level and at high altitude were observed in women aged between 20 and 29 years. This is in accordance with data reported in another study (Labrie et al. 1997). In women living at sea level, DHEA values at 60-69 years of age were reduced to $65 \%$ of the greatest value at $20-29$ years.

Table 4 Multivariate analysis to explain serum DHEAS concentrations in women resident at sea level or at high altitude

\section{DHEAS}

Place of residence Chronolgocial age Menopause Constant $\boldsymbol{\beta}$

$$
\begin{aligned}
-72 \cdot 81 & \pm 11 \cdot 32 \\
-2 \cdot 33 & \pm 0 \cdot 70 \\
-7 \cdot 61 & \pm 20 \cdot 46 \\
347 \cdot 68 & \pm 25 \cdot 51
\end{aligned}
$$

\section{$\boldsymbol{P}$}

$0 \cdot 0001$

$0 \cdot 001$

NS

$0 \cdot 0001$
Coefficient of determination $\left(R^{2}\right)=0 \cdot 38 ; P<0 \cdot 00001 . N=145 . \beta=$ Coefficient of regression (mean \pm S.E.). Place of residence: $0=$ sea level; $1=$ altitude. Menopause: $0=$ not; $1=$ yes. 
Table 5 Multivariate analysis to explain serum DHEA, DHEAS and androstenedione concentrations in women resident at high altitude

\begin{tabular}{|c|c|c|c|}
\hline & DHEAS & DHEA & Androstenedione \\
\hline Altitude at birth & $-0.001 \pm 0.009$ & $0 \cdot 0001 \pm 0 \cdot 0002$ & $-0.001 \pm 0.0002 *$ \\
\hline Years of residence & $0 \cdot 28 \pm 0 \cdot 39$ & $-0.02 \pm 0.01$ & $0 \cdot 0002 \pm 0 \cdot 006$ \\
\hline Chronological age & $-2 \cdot 24 \pm 0.59^{*}$ & $-0.017 \pm 0.015$ & $-0.038 \pm 0.009^{*}$ \\
\hline Constant & $185 \cdot 14 \pm 46 \cdot 46^{*}$ & $1.97 \pm 1 \cdot 18$ & $4 \cdot 44 \pm 0 \cdot 85^{*}$ \\
\hline$R^{2}$ & 0.19 & $0 \cdot 12$ & 0.36 \\
\hline$P$ & $0 \cdot 001$ & $0 \cdot 03$ & $0 \cdot 00001$ \\
\hline
\end{tabular}

Data represent coefficient of regression \pm S.E. $R^{2}$, coefficient of determination. $N=77$. Altitude at birth: $3000-4246 \mathrm{~m} .{ }^{*} P<0 \cdot 0001$.

This was similar to findings reported elsewhere in the literature (Labrie et al. 1997). However, in women living at high altitude, the reduction with age was of greater magnitude.

The maximal concentration of DHEAS occurred at later age in women resident at high altitude (30-39 years) than in those living at sea level (20-29 years). This could be related to the delayed presentation of adrenarche and delayed onset of puberty observed in girls living at high altitude compared with those living at sea level (Góñez et al. 1993, Gonzales et al. 1996). Early age at adrenopause could also be related to the early onset of menopause observed at high altitude (Gonzales \& Villena 1997). These data suggest that maturation is delayed and aging accelerated in women living at high altitude.

One of the most interesting findings is the increase in serum testosterone concentrations found at high altitude. This seems to be due to a high rate of metabolism from androstenedione to testosterone, and a low rate of metabolism from testosterone to estradiol. This has also been confirmed in men (Gonzales 1998b). As testosterone is an erythropoietic hormone, high concentrations of hemoglobin observed in the populations of the Andes of Peru may be a consequence of this increase. However, high hemoglobin concentrations may be also associated with chronic mountain sickness (Leon-Velarde \& Arregui 1994), therefore high testosterone concentrations may not afford the adaptive advantage that has been suggested previously (Gonzales 1998b).

In women, most peripheral androgens are produced by the metabolism of DHEA and DHEAS to testosterone and dihydrotestosterone in peripheral intracrine tissues (Phillips 1996, Labrie et al. 1997, 1998). According to our data, differences in serum adrenal androgen concentrations seem to be due to differences in the metabolism of these steroids. Indeed, the DHEAS/DHEA ratio was increased at high altitude.

One of the mechanisms of adrenarche is the reduction in activity of the enzyme $3 \beta$-hydroxysteroid dehydrogenase, inhibiting conversion of DHEA to androstenedione. In turn, synthesis and secretion of DHEA are increased (Gell et al. 1998). Activity of 3 $\beta$-hydroxysteroid dehydrogenase continues to decrease in the zona reticularis of the adrenal cortex in adults (Gell et al. 1998); however, it is unknown what happens during aging. The present study has demonstrated that activity of this enzyme, measured as the DHEA/androstenedione ratio, was not modified with aging, suggesting that mechanisms of adrenarche are different from those of the adrenopause.

The decline in the circulating concentrations of the adrenal androgens with aging seems to be due to a reduction in the mass of the reticularis zone of the adrenal cortex (Parker et al. 1997). However, studies on adrenal cells cultured in vitro demonstrate that the low concentrations of adrenal androgens associated with age seem to be more related to extra-adrenal than to intra-adrenal factors (Fearon et al. 1998). Life at high altitude is characterised by low barometric pressure and low oxygen pressure, and molecular oxygen is an obligatory substrate for the cytochrome P450c17 in the zona reticularis of the adrenal cortex (Roberts 1999).

Differences in serum concentrations of adrenal androgens between samples collected from women resident at sea level or at high altitude could be due to ethnic, smoking or environmental differences. Ethnicity has been demonstrated to affect adrenal androgen concentrations (Hill et al. 1976, Carmina et al. 1992, Kleerekoper et al. 1994, Manson et al. 2001). A recent study has demonstrated that African-American, but not white women had significantly lower concentrations of DHEAS with increasing age (Mansion et al. 2001). This does not seem to be the case in the present study. In fact, ethnic composition was similar in women studied at sea level and at high altitude.

Smoking is another factor associated with differences in adrenal androgen concentrations. Several studies have demonstrated greater serum adrenal androgen concentrations in women who are smokers (Cassidenti et al. 1992, Baron et al. 1995, Bancroft \& Cawood 1996, Johannes et al. 1999, Laughlin \& Barrett-Connor 2000). In the present study, differences in serum adrenal androgen concentrations between women resident at sea level or at high altitude were not attributable to smoking, because fewer than $1 \%$ of women from our sample were smokers. 
The finding that women at high altitude aged 60-70 years had serum concentrations of DHEA and DHEAS that were $50 \%$ of the value in those living at sea level suggests a major significance of aging at high altitude. This may explain the greater incidence of symptoms of disease among women aged over 65 years at high altitude than among those resident at sea level (Peru 1997, Gonzales 1998a), and the lower life expectancy among women at Cerro de Pasco $(4340 \mathrm{~m})$ than among women resident at sea level (León-Velarde \& Arregui 1994).

In summary, our findings show that changes in adrenal androgens with age seem to be associated with processes of maturation and aging. Serum concentrations were greatest in women aged 20-29 years, and then declined to low values after the age of 50 years. The early decline in adrenal androgen concentrations in women living at high altitude may suggest that aging is attained earlier at high altitude. Furthermore, serum adrenal androgen concentrations are associated with the well-being of aging persons (Ravaglia et al. 1996). The observation that, in the same age range (60-70 years), serum adrenal androgens in women living at high altitude were $50 \%$ of the values in those resident at sea level may therefore also suggest that greater aging processes operate at high altitude. This may be associated with both the greater prevalence of symptoms of disease in older women and the lower life expectancy at high altitude (León-Velarde \& Arregui 1994, Gonzales 1998a).

\section{Acknowledgements}

The authors thank Rosario Tapia and Amanda Córdova for their help in the field work. This study was partially supported by the Human Reproduction Programme of the World Health Organisation (WHO) and the Consejo Nacional de Ciencia y Tecnología (CONCYTEC) del Perú, and by the Instituto de Investigaciones de la Altura of the Universidad Peruana Cayetano Heredia.

\section{References}

Bancroft J \& Cawood EH 1996 Androgens and the menopause; a study of 40-60 year-old women. Clinical Endocrinology (Oxford) 45 577-587.

Baron JA, Comi RJ, Cryns V, Brinck-Johnsen T \& Mercer NG 1995 The effect of cigarette smoking on adrenal cortical hormones. Journal of Pharmacology and Experimental Therapeutics 272 151-155.

Berr C, Lafont S, Debuire B, Dartigues J-F \& Baulieu EE 1996 Relationship of dehydroepiandrosterone sulfate in the elderly with functional, psychological, and mental status, and short-term mortality: a French community-based study. PNAS $\mathbf{9 3}$ 13410-13415.

Birkenhager-Gillesse EG, Derksen J \& Lagaay AM 1994 Dehydroepiandrosterone sulphate (DHEAS) in the oldest old, aged 85 and over. Annals of the New York Academy of Sciences 719 $543-552$.
Bowles JT 1998 The evolution of aging: a new approach to an old problem of biology. Medical Hypotheses 51 179-221.

Carmina E, Koyama T, Chang L, Stanczyk FZ \& Lobo RA 1992 Does ethnicity influence the prevalence of adrenal hyperandrogenism and insulin resistance in polycystic ovary syndrome? Obstetrics and Gynecology 167 1807-1812.

Cassidenti DL, Pike MC, Vijod AG, Stanczyk FZ \& Lobo RA 1992 A reevaluation of estrogen status in postmenopausal women who smoke. American Journal of Obstetrics and Gynecology 166 1444-1448.

Corpas E, Harman SM \& Blackman MR 1993 Human growth hormone and human aging. Endocrine Reviews 14 20-39.

Dorland M, van Kooij RJ \& Te Velde ER 1998 General ageing and ovarian ageing. Maturitas 30 113-118.

Fearon U, Clarke D, McKenna TJ \& Cunningham SK 1998 Intra-adrenal factors are not involved in the differential control of cortisol and adrenal androgens in human adrenals. European Journal of Endocrinology 138 567-573.

Gell JS, Carr BR, Sasano H, Atkins B, Margraf L, Mason JI \& Rainey WE 1998 Adrenarche results from development of a 3 betahydroxysteroid dehydrogenase-deficient adrenal reticularis. Journal of Clinical Endocrinology and Metabolism 83 3695-3701.

Góñez C, Villena A \& Gonzales GF 1993 Serum adrenal androgens up to adrenarche in Peruvian children living at sea level and at high altitude. Journal of Endocrinology 136 517-523.

Gonzales GF 1998a Demographic, reproductive, morbidity and mortality patterns at high altitude. In: Progress in Mountain Medicine at High Altitude, pp 174-179. Eds H Ohno, T Kobayashi, S Masuyama \& M Nakashima. Tokorosawa: Japanese Society of Mountain Medicine.

Gonzales GF 1998 b Endocrine testicular function and adaptation to high altitude. Newsletter of the International Society of Mountain Medicine 8 5-7.

Gonzales GF \& Villena A 1997 Age at menopause in Central Andean Peruvian women. Menopause 4 32-38.

Gonzales GF, Villena A \& Ubilluz M 1996 Age at menarche in Peruvian girls at sea level and at high altitude: effect of ethnic background and socioeconomic status. American Journal of Human Biology 8 457-464.

Hill P, Wynder EL, Helman P, Hickman R, Rona G \& Kuno K 1976 Plasma hormone levels in different ethnic populations of women. Cancer Research 36 2297-2301.

Johannes CB, Stellato RK, Feldman HA, Longcope C \& McKinlay JB 1999 Relation of dehydroepiandrosterone and dehydroepiandrosterone sulfate with cardiovascular disease risk factors in women: longitudinal results from the Massachusetts Women's Health Study. Journal of Clinical Epidemiology $\mathbf{5 2}$ 95-103.

Kirkwood TB 1998 Ovarian ageing and the general biology of senescence. Maturitas 30 105-111.

Kleerekoper M, Nelson DA, Peterson EL, Wilson PS, Jacobsen G \& Longcope C 1994 Body composition and gonadal steroids in older white and black women. Journal of Clinical Endocrinology and Metabolism 79 775-779.

Labrie F, Belanger A, Cusan L, Gomez JL \& Candas B 1997 Marked decline in serum concentrations of adrenal C19 sex steroid precursors and conjugated androgen metabolites during aging. Journal of Clinical Endocrinology and Metabolism 82 2396-2402.

Labrie F, Belanger A, Van LT, Labrie C, Simard J, Cusan L, Gomez JL \& Candas B 1998 DHEA and the intracrine formation of androgens and estrogens in peripheral target tissues: its role during aging. Steroids 63 322-328.

Lamberts SW, van der Beld AW \& van der Lely AJ 1997 The endocrinology of aging. Science 278 419-424.

Laughlin GA \& Barrett-Connor E 2000 Sexual dimorphism in the influence of advanced aging on adrenal hormone levels: the Rancho Bernardo Study. Journal of Clinical Endocrinology and Metabolism $\mathbf{8 5}$ 3561-3568 
León-Velarde F \& Arregui A 1994 Desadaptación a la Vida en las Grandes Alturas, pp 48-64. Lima: IFEA/UPCH.

León-Velarde F, Ramos MA, Hernández JA, De Idiaquez D, Muñóz LS, Gaffo A, Córdova S, Durand D \& Monge C 1997 The role of menopause in the development of chronic mountain sickness. American Journal of Physiology 272 R90-R94.

Manson JM, Sammel MD, Freeman EW \& Grisso JA 2001 Racial differences in sex hormone levels in women approaching the transition to menopause. Fertility and Sterility 75 297-304.

Morales AJ, Nolan JJ, Nelson JC \& Yen SSC 1994 Effects of replacement dose of dehydroepiandrosterone in men and women of advancing age. Journal of Clinical Endocrinology and Metabolism 78 1360-1367.

Morales AJ, Haubrich RH, Hwang JY, Asakura H \& Yen SSC 1998 The effect of six months treatment with a $100 \mathrm{mg}$ daily dose of dehydroepiandrosterone (DHEA) on circulating sex steroids, body composition and muscle strength in age-advanced men and women. Clinical Endocrinology (Oxford) 49 421-432.

Parker CR Jr, Mixon RL, Brissie RM \& Grizzle WE 1997 Aging alters zonation in the adrenal cortex of men. Journal of Clinical Endocrinology and Metabolism 82 3898-3901.

PERU 1997 Caracterí sticas de Salud de la Población: Encuesta Nacional de Hogares, 1996, 182 pp. Lima: Instituto Nacional de Estadí stica e Informática.

Phillips GB 1996 Relationship between serum dehydroepiandrosterone sulfate, androstenedione, and sex hormones in men and women. European Journal of Endocrinology 134 201-206.

Ravaglia G, Forti P, Maioli F, Boschi F, Bernardi M, Pratelli L, Pizzoferrato A \& Gasbarrini G 1996 The relationship of dehydroepiandrosterone sulfate (DHEAS) to endocrine-metabolic parameters and functional status in the oldest-old. Results from an Italian study on healthy free-living over-ninety-year-olds. Journal of Clinical Endocrinology and Metabolism 81 1173-1178.

Roberts E 1999 The importance of being dehydroepiandrosterone sulfate (in the blood of primates): a longer and healthier life? Biochemical Pharmacology 57 329-346.

Semezuk M 1998 Selected endocrinological problems in mature and elderly men. Ginekologia Polska 69 367-373.

Snowdon DA 1990 Early natural menopause and the duration of postmenopausal life. Journal of the American Geriatrics Society 38 402-408.

Snowdon DA, Kane RL, Beeson WL, Burke GL, Sprafka JM, Potter J, Iso H, Jacobs DR Jr \& Phillips RL 1989 Is early natural menopause a biologic marker of health and aging? American Journal of Public Health 79 709-714.

Soules MR, Battaglia DE \& Klein NA 1998 Inhibin and reproductive aging in women. Maturitas 30 193-204.

te Velde ER, Dorland M \& Broekmans FJ 1998a Age at menopause as a marker of reproductive ageing. Maturitas $\mathbf{3 0}$ $119-125$.

te Velde ER, Scheffer GJ, Dorland M, Broekmans FJ \& Fauser BC 19986 Developmental and endocrine aspects of normal ovarian aging. Molecular and Cellular Endocrinology 145 67-73.

Vermeulen A 1997 Juvenile hormones, reality or myth? Verhandelingen - Koninklijke Academie voor Geneeskunde van Belgie 59 19-33.

WHO 1996 Research on the menopause in the 1990s, p 107. Geneva: WHO.

Received 11 December 2001

Accepted 14 January 2002 